\title{
SERVICE ROBOT CONTROL AND WIRELESS NETWORK CONSTRUCTION
}

\section{Valentin Pryanichnikov, Eugene Prysev, Stanislav Eprikov, Oleg Punenkov}

Abstract: While building a supervisor robot control, even in extreme conditions, WiFi wireless communications are allowed (for example, we implemented multi-stream video transmission for the Brokk-type robots). However, in this case there are two problems - it is necessary to foresee that the attenuation of the signal upon detection of coverage areas and the provision of switching control using the automatic return algorithm. In our work, a number of approaches to assessing the quality and quality of work were proposed. An experimental study of this parameter was carried out in robotized systems (IINET RGGU - Keldysh Institute of Applied Mathematics RAS), consisting of many rooms in which the control of mobile service robots Amur-307, Amur-105, Robotino and others. To control the service robot, seamless roaming (handover) technology was implemented - providing Wi-Fi coverage, with access to several access points (clients), switching between zones, switching from one point to another without losing the signal [1]. When designing such a seamless wireless network, one of the most important conditions affecting the quality of the built network infrastructure is to determine the degree of attenuation of the wireless signal. The paper is based on the report, presented on the DAAAM-2019 symposium

Key words: mobile service robots Amur type, WiFi seamless coverage for supervisory control, sensorics.
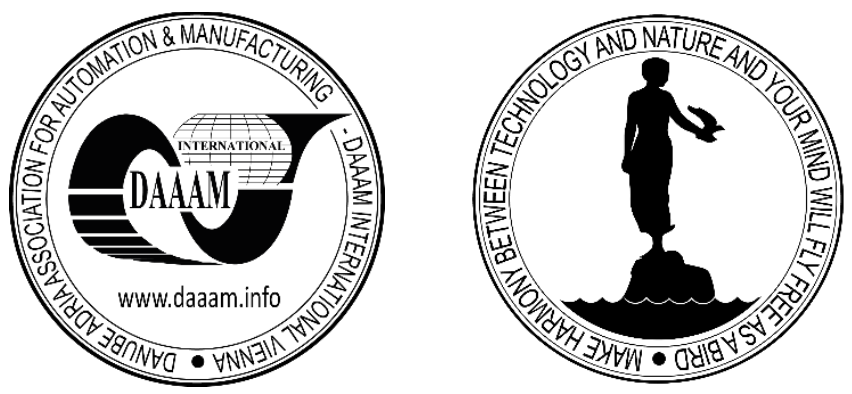

Authors' data: Pryanichnikov, V[alentin]*; Prysev, E[ugene]**; PhD student Eprikov, S[tanislav]*; Punenkov, O[leg]***, * Keldysh Institute of Applied Mathematics, RAS, Miusskaya sq., 4, 125047, Moscow, Russia, ** IINET RSUH, Miusskaya sq. 6, 125047, Moscow, Russia, *** Moscow State University of Technology "STANKIN", Vadkovsky per., 3a, 127994, Moscow, Russia

This Publication has to be referred as: Pryanichnikov, V[alentin]; Prysev, E[vgeny]; Eprikov, S[tanislav] \& Punenkov, O[leg] (2019). Service Robot Control and Wireless Network Construction, Chapter 32 in DAAAM International Scientific Book 2019, pp.367-376, B. Katalinic (Ed.), Published by DAAAM International, ISBN 978-3902734-24-2, ISSN 1726-9687, Vienna, Austria

DOI: $10.2507 /$ daaam.scibook.2019.32 
Pryanichnikov, V.; Prysev, E.; Eprikov, S. \& Punenkov, O.: Service Robot Control ...

\section{Introduction}

When building a supervisor robot control, even in extreme conditions, Wi-Fi wireless communication is allowed (for example, we implemented multi-stream video transmission for the Brock-type EMERCOM robots). However, in this case there are two problems - it is necessary to foresee that the attenuation of the signal upon detection of coverage areas and the provision of switching control using the automatic return algorithm. In our work, a number of approaches to assessing the quality and quality of work were proposed. An experimental study of this parameter was carried out in robotized systems (MINOT RGGU - Keldysh Institute of Applied Mathematics), consisting of many rooms in which the control of mobile service robots Amur-307, Amur-105, Robotino and others.

To control the service robot, seamless roaming (handover) technology was implemented - providing Wi-Fi coverage, with access to several access points (clients), switching between zones, switching from one point to another without losing the signal [1]. When designing such a seamless wireless network, one of the most important conditions affecting the quality of the built network infrastructure is to determine the degree of attenuation of the wireless signal.

With the help of specialized software, a survey of parts of the building was conducted. Wall types and the actual scale of the plan were identified, and inconsistencies were corrected. D-Link DWL-3200AP provides the optimal location of access points to the most important signal transmission zones, taking into account the existing wired infrastructure. To reduce the level of interference, it was decided to use non-overlapping channels $(1,6,11)$ at $2.4 \mathrm{GHz}$.

The implementation of the project to cover the premises with uninterrupted WiFi signal coverage allowed not only to manage service robots, but also to create a public Wi-Fi infrastructure for visitors without the need for reconfiguration.

The first step in building a wireless network is to design it. With the help of special solutions, a radio survey of all rooms is carried out, their plan is drawn up, optimal places are chosen for the installation of access points, taking into account the absorbing capabilities of walls, doors and other objects.

\section{Creating a project to calculate the control signal coverage}

The project of a wireless Wi-Fi network should always include a radio inspection of the object at the design stage and prior to the installation of the equipment. Radio testing is carried out at the design stage to determine the configuration and optimal installation sites of equipment to ensure uninterrupted and high-quality network operation. There are two main types of radio survey:

1. Passive examination. Conducted with test access points that are selected to build the network. The level of the received signal is measured, and the signals of all access points in the study zone are recorded in the $2.4 \mathrm{GHz}$ and $5 \mathrm{GHz}$ bands.

2. Active examination. It implies the additional use of metering devices that imitate a real subscriber device (mobile phone, tablet, laptop, barcode scanner) communicating 
with the access point. Measurement of real data: connection speed, packet loss, switching between points, etc., diagnostics of client devices.

In addition to surveys using actual measurements at the site, a radio survey can be used to design still non-deployed Wi-Fi networks. This type of survey is called "predictive" or "virtual", since Wi-Fi characteristics are calculated for a virtual model of the environment created by the user. The process of creating and configuring a virtual environment, choosing the location of virtual access points (APs) and analyzing a simulated Wi-Fi network is usually called "RF-planning" [2]. Prior to the beginning of the radio survey, a plan of the robotarium, a department, was received, on which a Wi-Fi network is expected. A study was conducted of the premises, the accuracy of the plan, the thickness and height of the walls were determined, as well as columns and fire doors were marked. The plan (floor) is a schematic of the object, presented as a drawing with special designations (for example, a BTI plan). The designations used when creating floor plans of an object are called graphical symbol (GS) and are governed in various standarts: GOST 21.201-2011 Project documentation system for construction (SPDS), Conventional graphic images of elements of buildings, structures and structures; GOST 21.205-93 SPDS, Symbols of elements of sanitary and technical systems.

Based on the information obtained during the analysis of these standards, a table of symbols used in terms of premises was created (Table 1).

\begin{tabular}{|c|c|c|c|}
\hline Name of the object & GS facility on the plan & Standard & Note \\
\hline Ladder (lower march) & & $\begin{array}{l}\text { GOST 21.201-2011, p.ti } \\
4.6\end{array}$ & $\begin{array}{l}\text { On the plans of the stairs } \\
\text { the arrow indicates the } \\
\text { direction of raising the } \\
\text { march. }\end{array}$ \\
\hline $\begin{array}{l}\text { Ladder } \quad \text { (intermediate } \\
\text { marches) }\end{array}$ & e & $\begin{array}{ll}\text { GOST 21.201-2011, p.t } \\
4.6\end{array}$ & $\begin{array}{l}\text { On the plans of the stairs } \\
\text { the arrow indicates the } \\
\text { direction of raising the } \\
\text { march. }\end{array}$ \\
\hline Ladder (Upper March) & & $\begin{array}{ll}\text { GOST } 21.201-2011, & \text { p.t } \\
4.6 & \end{array}$ & $\begin{array}{l}\text { On the plans of the stairs } \\
\text { the arrow indicates the } \\
\text { direction of raising the } \\
\text { march. }\end{array}$ \\
\hline Column (support) & $\sum$ & $\begin{array}{l}\text { GOST 21.201-2011, p. } \\
4.2\end{array}$ & \\
\hline Sink, sink & & GOST 21.205-93, tab. 2 & \\
\hline Toilet & (o) & GOST 21.205-93, tab. 2 & \\
\hline Window opening & $\Rightarrow$ & $\begin{array}{ll}\text { GOST } & \text { 21.201-2011, } \\
\text { Clause4.4 } & \end{array}$ & \\
\hline $\begin{array}{l}\text { Room number and its } \\
\text { area }\end{array}$ & $s \frac{3}{11,5}$ & Examples of plans & \\
\hline
\end{tabular}

Table 1. GS, used in terms of premises 
When designing a seamless wireless network, it is worth considering one of the most important conditions affecting the quality of the built network infrastructure determining the degree of attenuation of the wireless signal.

In order to take into account this important factor, a model of radio propagation in rooms is being developed. When building this model, the following factors should be considered:

- Signal interference with various electrical devices has a significant effect on signal propagation.

- Attenuation of a radio signal or its complete loss may occur as a result of passing through various obstacles or reflections from them.

Obstacles include walls, beams, furniture, different types of doors, columns. Such objects, being on the path of radio signal propagation, partially / significantly (depending on the obstacle) absorb or reflect it, which leads to a deterioration in the signal quality.

Each obstacle in the zone of propagation of a signal reduces its power. The more obstacles are there, the worse the signal becomes. It is also worth noting that the WiFi signal not only tries to bend around an obstacle, but also passes through it, which leads to additional reflection and absorption of a part of the original signal. Quality affects not only the number of walls located on the signal propagation path, but also their thickness.

There are materials with a different signal absorption coefficient. For example, wood, plastic, ordinary glass, drywall refer to materials with low absorption. Tinted glass, water (large aquarium), brick, plaster are materials with medium absorption. Materials with a high absorption coefficient, which have a strong negative effect on the signal, include metal (iron doors, aluminum and steel beams), concrete (inside which there is a reinforcing lattice), and ceramics. Indoors, mirrors can also cause radio signal interference (strongly reflect the signal) and tinted windows.

The table below shows the loss of Wi-Fi signal efficiency when passing through various environments. The values (not absolute, but approximate) are given for a wireless network operating in the $2.4 \mathrm{GHz}$ frequency band (Table 2).

\begin{tabular}{|l|l|l|}
\hline Obstacle & Additional loss, dB & Effective distance \\
\hline Open space & 0 & $100 \%$ \\
\hline $\begin{array}{l}\text { Window without tinting (no metallized } \\
\text { coating) }\end{array}$ & 3 & $70 \%$ \\
\hline Window tinted (metallized coating) & $5-8$ & $50 \%$ \\
\hline Wooden wall & 10 & $30 \%$ \\
\hline Interroom wall $(15.2 \mathrm{~cm})$ & $15-20$ & $15 \%$ \\
\hline Bearing wall $(30.5 \mathrm{~cm})$ & $20-25$ & $10 \%$ \\
\hline Concrete floor / ceiling & $15-25$ & $10-15 \%$ \\
\hline Monolithic reinforced concrete floor & $20-25$ & $10 \%$ \\
\hline
\end{tabular}

Table 2. Wi-Fi signal efficiency loss 
Effective distance means how much the range of a Wi-Fi signal will decrease after passing the corresponding obstacle compared to open space [3].

To obtain a more extensive and accurate model of radio signal propagation, four main types of walls were identified that were used when working with the floor plan:

- $\quad$ Type 1 - thin partitions up to $10 \mathrm{~cm}$ thick (this type also includes windows inside the cabinets).

- $\quad$ Type 2 - interior walls with a thickness of $10 \mathrm{~cm}$ to $20 \mathrm{~cm}$, consisting of drywall. - Type 3 - interior walls with a thickness of $10 \mathrm{~cm}$ to $20 \mathrm{~cm}$, consisting of concrete, sheathed with plasterboard.

- $\quad$ Type 4 - concrete and brick walls with a thickness of $20 \mathrm{~cm}$.

Considering these four views, the corresponding marks were made on the plans, showing where the type of walls is and their width.

Formulated network requirements include:

- $\quad$ Number of users per point at least 10

- Acceptable signal level, which is enough for both remote control of robots and Internet surfing (up to $-60 \mathrm{dBm}$ )

- $\quad$ Seamless roaming

The initial plan was marked by the area in which the use of a service robot is planned, therefore it is necessary to ensure uninterrupted wireless network coverage (Figure 2).

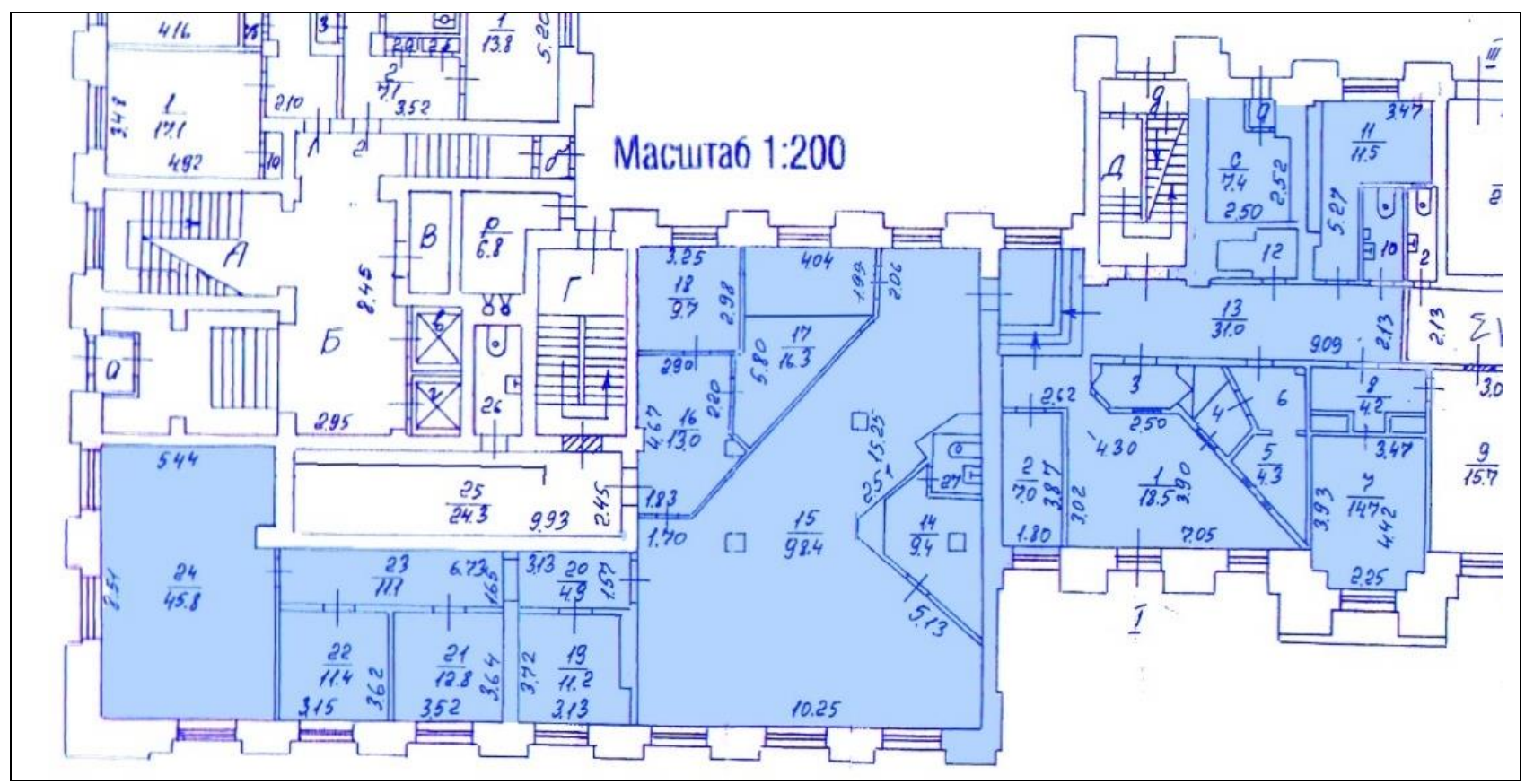

Fig. 1. The working area of the service robot

With the help of specialized software, a predictive survey of this part of the building was carried out. The types of walls and the actual scale of the plan were indicated, as well as inconsistencies in the arrangement of some structures (Fig. 2.). 
Pryanichnikov, V.; Prysev, E.; Eprikov, S. \& Punenkov, O.: Service Robot Control ...

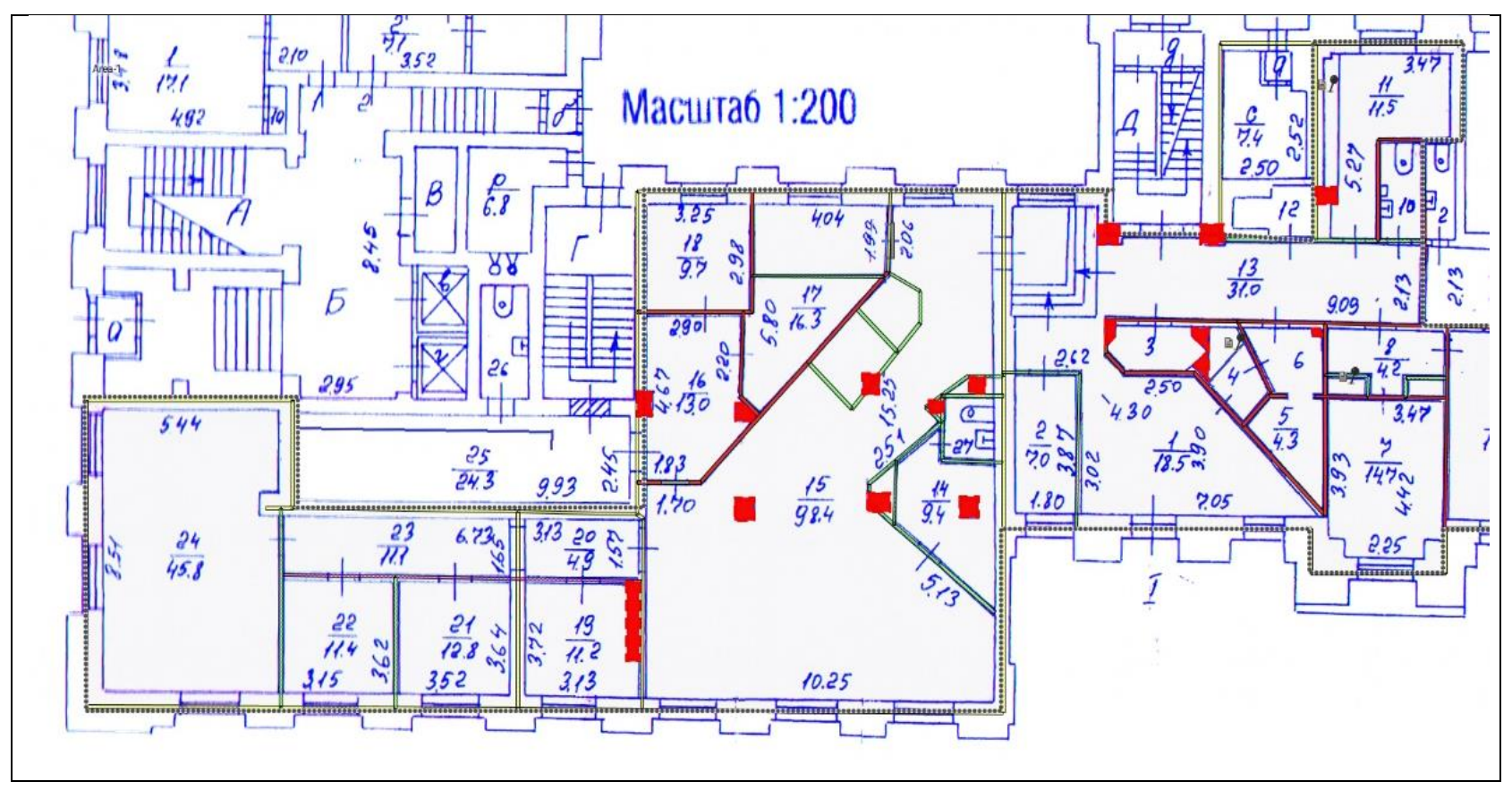

Fig. 2. Indication of wall types on the floor plan

In order to check the quality of the coating, a passive survey was conducted with test access points. Measurements were made of the received signal level in the study zone in the $2.4 \mathrm{GHz}$ band. The access points (AP) D-Link DWL-3200AP available at the customer participated in the modeling of the coverage. Based on the fact that there were 4 access points, their optimal location was determined in terms of covering the most important signal propagation zones (Fig. 3.). Also the existing wired infrastructure was taken into account to minimize the cost of installation work. To reduce the level of interference, it was decided to use non-overlapping channels $(1,6$, 11) at $2.4 \mathrm{GHz}$.

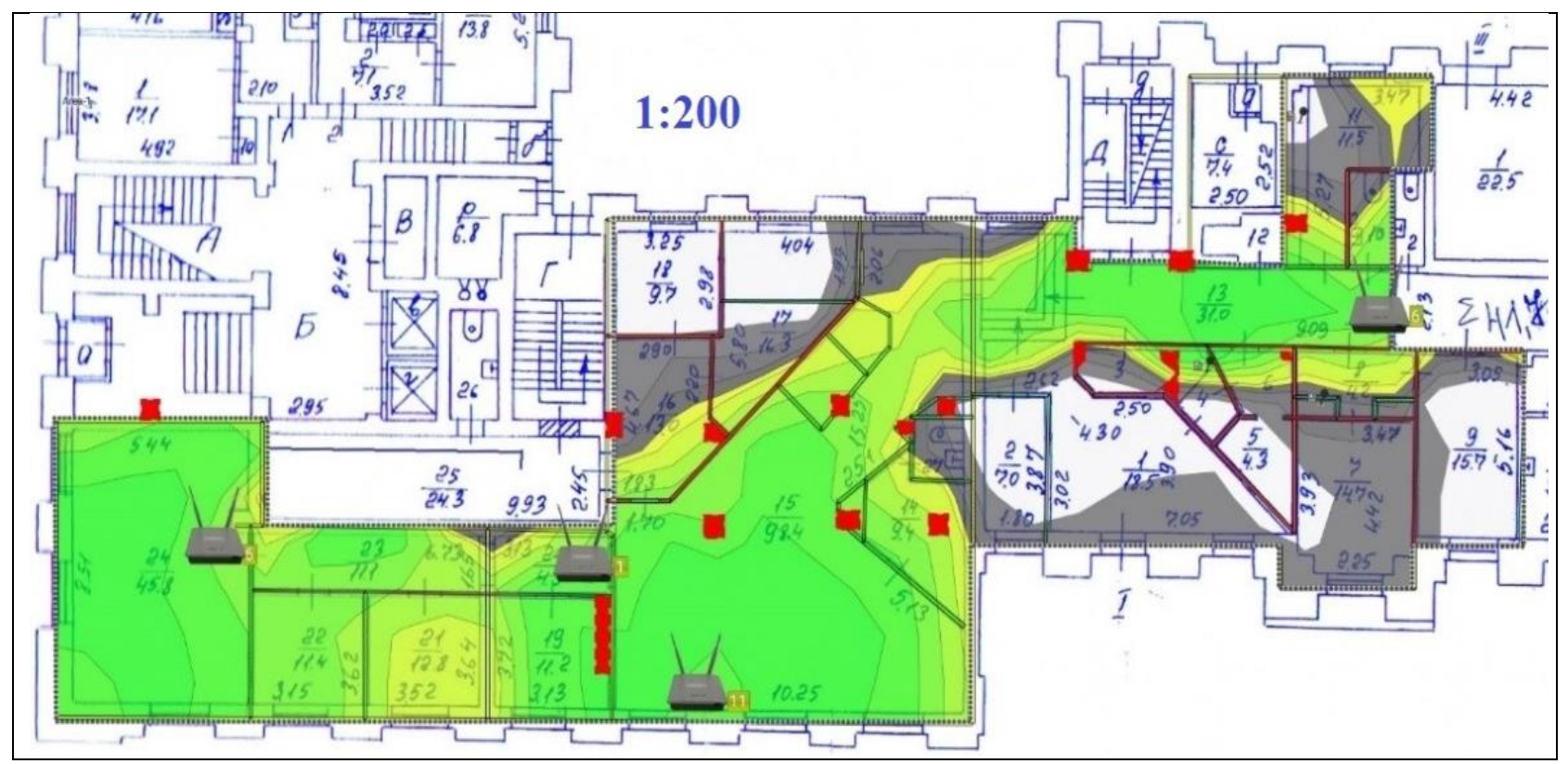

Fig. 3. The level of signal propagation using four APs DWL-3200AP 


\section{Selection and comparison of equipment for the tasks}

Further, an analysis of the telecommunications equipment market was carried out in order to select the AP models most suitable for the tasks assigned and the following APs were considered: Ubiquiti UniFi AP (UAP), Ubiquiti UniFi AP LR (UAP-AC-LR), Ubiquiti UniFi AP Pro (UAP-AC -PRO), Ubiquiti UniFi AP AC Lite (UAP-AC-LITE). Table 3 shows the price range for these AP models, and Table 4 compares the characteristics of these Aps.

Consider the signal level when using different options. Hereinafter, the name of the pictures in brackets will indicate the signal level. For example, "AC LITE x 5 (-60 $\mathrm{dBm}$ )" means that the signal level of $-60 \mathrm{dBm} \ldots-50 \mathrm{dBm}$ is highlighted in gray, the signal of the best level is colored in color.

\begin{tabular}{|l|l|l|l|}
\hline AP Model & $\begin{array}{l}\text { Cost of } \mathbf{1} \text { pcs., } \\
\text { RUR }\end{array}$ & $\begin{array}{l}\text { The cost of a set } \\
\text { of 3 pieces., RUR }\end{array}$ & $\begin{array}{l}\text { The cost of a set } \\
\text { of 5 pcs., RUR }\end{array}$ \\
\hline Ubiquiti UniFi AP & 4520 & $11800-13400$ & - \\
\hline Ubiquiti UniFi AP LR & 7200 & 17379 & 32210 \\
\hline Ubiquiti UniFi AP PRO & 9830 & $28050-29350$ & $46300-47716$ \\
\hline $\begin{array}{l}\text { Ubiquiti UniFi AP AC } \\
\text { Lite }\end{array}$ & - & $25650-26708$ \\
\hline
\end{tabular}

Table 3. Estimated cost of equipment on the market

Another example: "AC LITE x $5(-70 \mathrm{dBm})$ " means that the signal level of -70 $\mathrm{dBm} . . .60 \mathrm{dBm}$ is highlighted in gray, the signal of the best level is in color.

1. 5 UAP AC Lite access points. (Fig. 4. a)

2. 5 UAP AC LR access points. (Fig. 4. b)

3. 5 UAP AC PRO access points. (Fig. 4. c)

4. 5 UAP AP access points. (Fig. 4. d)

Let us consider the signal level by using various options. Hereinafter, the name of the pictures in brackets will indicate the signal level. For example, "AC LITE x 5 ($60 \mathrm{dBm}$ )" means that the signal level of $-60 \mathrm{dBm}$... $-50 \mathrm{dBm}$ is highlighted in gray , the signal of the best level is colored in color.

Analyzing the data obtained, the customer was given the following recommendations on the choice of equipment:

- It does not make sense to consider UAP AP, since it does not know how to work in the $5 \mathrm{GHz}$ band, and in the future, if there is a need to connect, besides robots, also visitors, it is better to "unload" the $2.4 \mathrm{GHz}$ band for smooth work with robots. On the other hand, for 20 tr. one can take 5 of these access points.

- $\quad$ UAP AC LR and UAP AC PRO show almost identical results when using three points, and when using five. Therefore, it makes no sense to overpay for the PRO version. 
Pryanichnikov, V.; Prysev, E.; Eprikov, S. \& Punenkov, O.: Service Robot Control ...

When choosing between UAP AC Lite and UAP AC LR, you should rely on the budget and the number of points.

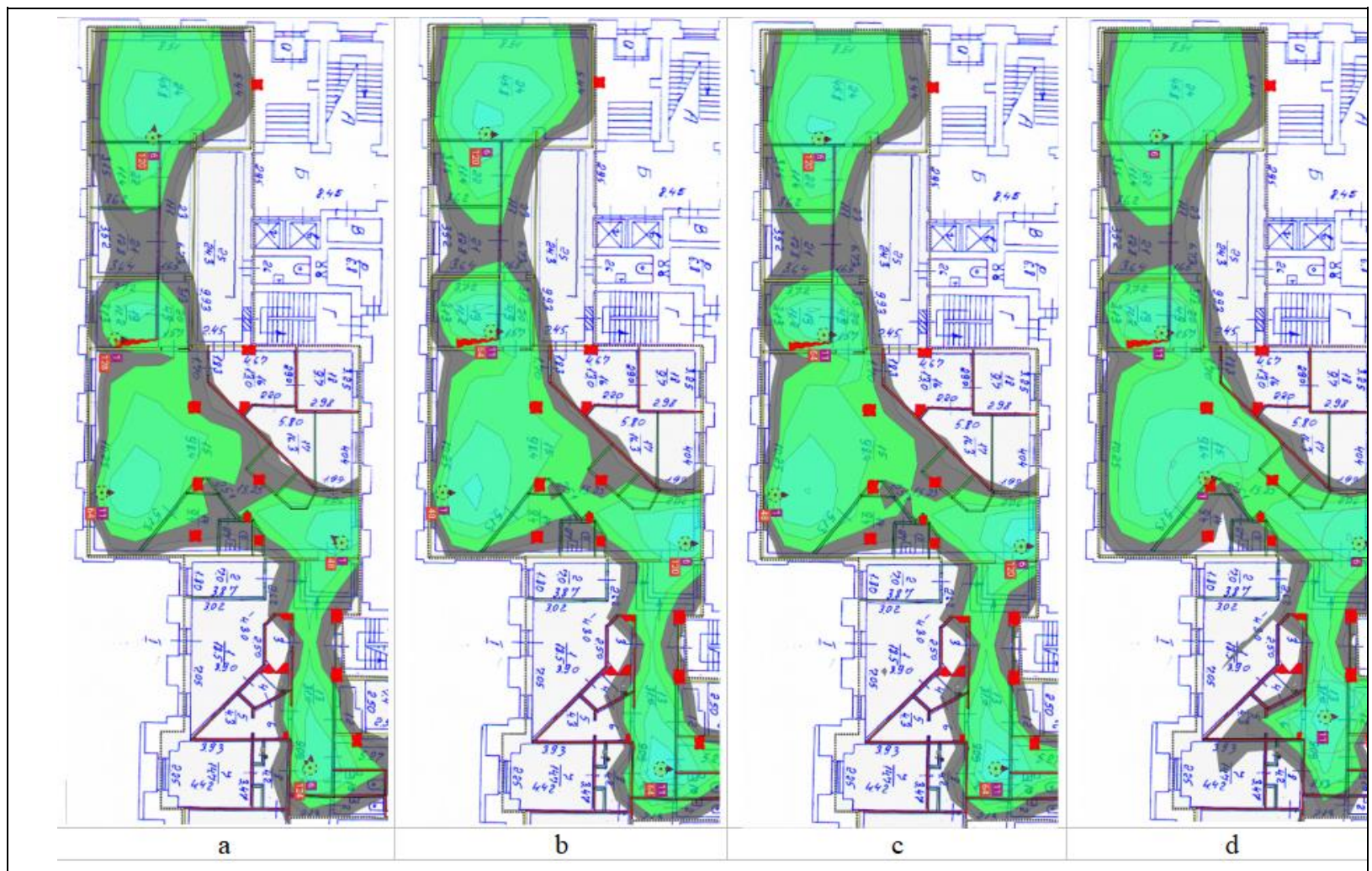

Fig. 4. Signal strength when using 5 devices: a. UAP AC Lite access points; b. UAP AC LR access points; c. UAP AC PRO; d. UAP AP access points.

\section{Conclusion}

In this work, a survey was conducted of a rather large room of a robotarium at the IINET RSUH with the subsequent installation of access points and a passive radio survey that allowed testing the simulated coverage.

Thus, confirmation was obtained of the effectiveness of the proposed method of building room models for designing sustainable supervisory control of a group of mobile robots for various purposes - service, for telemedicine, for surveying premises in extreme situations, including network deployment using the repeater robots themselves. Studies are also based on other works of our team - see [4-11].

\section{References}

Zyxel. Access points "[Electronic resource] - Access mode: https://kb.zyxel.ru/hc/ru/articles/115002584514- Description of the modes of operation- wireless- point- access- Wi Fi, free. Reference date: 07/20/2018 TP-Link. Building a WLAN "[Electronic resource] - Access Mode: https://itnan.ru/post.php?c=1\&p=335674, free. Reference date: 07/20/2018 
Zyxel. Wi-Fi "[Electronic resource] - Access mode: https://kb.zyxel.ru/hc/ru/articles/115002572093- Ratio-attenuation ratios- Signal- WiFi- through passage- through- various- environments, free. Reference date: 07/25/2018 Pryanichnikov V.E., Aryskin A.A., Eprikov S.R., Kirsanov K.B., Khelemendik R.V., Ksenzenko A.Ya., Prysev E.A., Travushkin A.S. (2017). Processing of Consumables, Proceedings of the 28th DAAAM International Symposium, pp. 1202-1207, B. Katalinic (Ed.), Published by DAAAM International, ISBN 978-3-902734-11 -2, ISSN 1726-9679, Vienna, Austria. DOI: 10.2507 / 28th.daaam.proceedings.167

Ksenzenko A.Ya., Marzanov Yu.S., Prysev E.A., Pryanichnikov V.E., Chernyshev V.V. Prototyping of contactless data exchange and energy supply of a group of underwater satellite robots with a base station walking along the bottom. Extreme Robotics. // Collection of theses of the International Scientific and Technical Conference. - SPb: Gangut Publishing and Printing Complex, 2017.- 272 p., P. 268269. ISBN 978-5-85875-522-7. (Extreme robotics. // Abstracts of the International Scientific and Technological Conference. - Saint-Petersburg: "Gangut", 2017. - 272p. URL: http://er.rtc.ru/images/docs/Sbornik_tezisov_ER_2017.pdf

Bogdanovich A.V., Kirsanov K.B., Pryanichnikov V.E., Helemendik R.V. Software and hardware components of intelligent service mobile robots / Information-measuring and control systems (Issue. Intelligent adaptive robots, V. 14, No. 1-2, 2019), M .: Radiotechnika, 2018, V. 16, No. 12 ,. p.33-39.

Khelemendik R. V., Pryanichnikov V. E. On IGEC technology and its application in the study of chess endings // Scientific service on the Internet: Proceedings of the XIX all-Russian scientific conference (September 19-24, 2017, Novorossiysk). - Moscow: KIAM Keldysh Inst., $2017 . \quad$ Pp. 446-455. - URL: http://keldysh.ru/abrau/2017/proc.pdf

Shipovalov E. A., Pryanichnikov V. E. Auto-planning of missions of mobile robots by onboard computer complexes with hybrid architecture // Extreme robotics. / Collection of abstracts of the International scientific and technical conference. - St. Petersburg: Publishing and printing complex "Gangut", 2017. - Pp. 119-120.6.

Kirilchenko A. A., Pryanichnikov V. E., Rogozin K. V. Limits of reliability and reliability of evidence. Skepticism in mathematics, functions, traditions // Informationmeasuring and control systems. - 2013. - Vol. 11, No. 4. Pp. 57-65. ISSN 2070-0814. Pryanichnikov V. E. Artificial intelligence and software and hardware robotic systems. Information-measuring and control systems. - 2018. - Vol. 16, No. 12. - Pp. 3-11. ISSN 2070-0814.

Pryanichnikov V.E., Aryskin A.A., Eprikov S.R., Kirsanov K.B., Khelemendik R.V., Ksenzenko A.Ya., Prysev E.A., Travushkin A. S. (2017). Technology of Multi-Agent 
Pryanichnikov, V.; Prysev, E.; Eprikov, S. \& Punenkov, O.: Service Robot Control ... Control for Industrial Automation with Logical Processing of Contradictions, Proceedings of the 28th DAAAM International Symposium, pp.1202-1207, B. Katalinic (Ed.), Published by DAAAM International, ISBN 978-3-902734-11-2, ISSN 1726-9679, Vienna, Austria. DOI:10.2507/28th.daaam.proceedings.167 